\title{
Trends in the use of Yoga and Naturopathy based lifestyle clinics for the management of Non-communicable diseases (NCDs) in Tamilnadu, South India
}

\author{
K. Maheshkumar ${ }^{\mathrm{a}, *}$, V. Venugopal ${ }^{\mathrm{b}}$, S. Poonguzhali ${ }^{\mathrm{c}}$, N. Mangaiarkarasi ${ }^{\mathrm{d}}$, S.T. Venkateswaran $^{\mathrm{e}}$, \\ N. Manavalan ${ }^{\mathrm{f}}$ \\ ${ }^{a}$ Department of Physiology \& Biochemistry, Govt. Yoga \& Naturopathy Medical College \& Hospital, Tamilnadu Dr.MGR Medical University, Chennai, 600106, India \\ ${ }^{\mathrm{b}}$ Department of Yoga, Govt.Yoga \& Naturopathy Medical College \& Hospital, Tamilnadu Dr.MGR Medical University Chennai, 600106, India \\ ${ }^{\mathrm{c}}$ Department of Community Medicine, Govt.Yoga \& Naturopathy Medical College \& Hospital, Tamilnadu Dr.MGR Medical University, Chennai, 600106, India \\ ${ }^{\mathrm{d}}$ Department of Acupuncture \& Energy Medicine, Govt. Yoga \& Naturopathy Medical College \& Hospital, Tamilnadu Dr.MGR Medical University, Chennai, 600106, India \\ ${ }^{\mathrm{e}}$ Department of Yoga, Govt.Yoga \& Naturopathy Medical College \& Hospital, Tamilnadu Dr.MGR Medical University, Chennai, 600106, India \\ ${ }^{\mathrm{f}}$ Department of Naturopathy, Govt.Yoga \& Naturopathy Medical College \& Hospital, Tamilnadu Dr.MGR Medical University, Chennai, 600106, India
}

\section{A R T I C L E I N F O}

\section{Keywords:}

Yoga

Naturopathy

Lifestyle clinics

Non-communicable diseases (NCDs)

\begin{abstract}
A B S T R A C T
Objectives: Prevalence of Non-communicable Diseases (NCDs) are on the increase and there is an urgent need for novel and effective treatment modalities in the management of NCDs. Objective of the current study is to understand the success of one such 'novel' Yoga and Naturopathy based 'Lifestyle clinic' model, executed at various government rural and urban settings in Tamil Nadu, South India. The patient trends and health conditions with which they had visited these Yoga and Naturopathy centers are presented in this article.

Method: We retrospectively analyzed the data abstracted from various government Yoga \& Naturopathy centers/ Lifestyle clinics in Tamil Nadu, which includes the total number of outpatients, name and frequency of diseases diagnosed and treatments offered.

Results: Total number of outpatients who had approached the centers/Lifestyle clinics between the period of 2015 and 2018 was 8,914,820. There was a positive increase in the trend of the number of patients who visited various Yoga and Naturopathy centers on a year-on-year basis since 2015. Of the patients identified, most patients visited the rural centers- National Rural Health Mission (NRHM) (44\%). Patients who had visited other centers like District Headquarters Hospital (DHQHpl) and Medical College Hospitals (MCH) were 31\% and 25\% respectively.

Conclusion: Our study suggests that the Yoga and Naturopathy based 'Lifestyle clinic model' is successful in the community and there is a positive increase in trend among patients for utilizing these government centers. Further analysis of the characteristics of patients getting treated would help future researchers to implement stronger clinical evidence and its implementation on a larger scale.
\end{abstract}

\section{Background}

There is a substantial increase in the use of complementary and alternative medicine (CAM) over the past few decades within and outside the mainstream health care system. ${ }^{1}$ Several international studies have demonstrated this trend, both in the general population and in different patients groups. ${ }^{2-7}$ Owing to the increase in usage of the traditional CAM therapies, World Health Organisation (WHO) has developed a global strategy, setting-up the benchmarks in clinical practice of traditional \& complementary therapies (T\&CM). ${ }^{8}$ The primary goals of which is not just to promote safe and effective use of traditional medicine, but also to harness the potential contributions of traditional medicine and integrate it into healthcare systems, wherever appropriate. ${ }^{9}$ CAM therapies are popularly used as a part of disease management in conjunction with conventional medicine. CAM usage is more driven by values and beliefs, than due to dissatisfaction with biomedicine. ${ }^{10}$ Economic and socio-cultural factors greatly influence the use of any type of medicine, which is also applicable to CAM therapies. For instance, in underdeveloped societies where access to biomedical services are not adequate, there is pervasive reliance on

\footnotetext{
${ }^{*}$ Corresponding author.

E-mail address: doctor.mahesh1985@gmail.com (K. Maheshkumar).
} 
traditional healers, even in case of serious illness. ${ }^{11}$ However, in affluent countries, where biomedical services are more readily accessible, CAM is substantially used for disease prevention and health promotion. ${ }^{12}$

Yoga and Naturopathy are popular CAM therapies commonly practiced across the world. In South India, the state of Tamil Nadu came up with a clinical model to curb the rampant prevalence of lifestyle disorders by introducing 'Yoga \& Naturopathy- Lifestyle clinics' across all 33 districts of the state. Patients here are treated as outpatients for various diseases with Yoga and Naturopathy therapies. Yoga is a way of life, ${ }^{13}$ consisting of moral and self-discipline codes called yama and niyama, alongside other mind-body practices like asana, pranayama, and meditation. Yoga as a therapy, thus promotes physical, mental and social wellbeing, incorporating health in all aspects as defined by the World Health Organisation (WHO). More specifically, Yoga is found to be effective in the management of many non-communicable psychosomatic disorders. ${ }^{14-16}$ Likewise, Naturopathy consists of therapies using natural elements; Hydrotherapy using water, ${ }^{17}$ heliotherapy using sun, ${ }^{18}$ mud therapy, ${ }^{19}$ chromotherapy using colours, ${ }^{20}$ magnetotherapy ${ }^{21}$ manipulative therapy, ${ }^{22}$ fasting therapy, ${ }^{23}$ diet therapy ${ }^{24}$ (includes plant-based natural supplements), acupuncture, acupressure with reflexology, ${ }^{25}$ etc. Naturopathy by definition is more than a system of curing aches and pains and is more a 'way of life'. ${ }^{26}$ Naturopathy believes in treating the root cause of the disease and not just the symptoms. ${ }^{27}$ Combination of Yoga therapy and Naturopathy are the best-suited CAM therapy of choice for our specialized 'Lifestyle clinic' model meant to curb NCDs. The patients who visit the clinic get guidance and counselling on lifestyle modifications alongside Yoga \& Naturopathy treatments. Since the start of these Lifestyle clinics, they have been running successfully in treating patients as well as spreading knowledge and awareness about health \& disease among the public. This paper aims to provide an overview of the trend existing over the years among patients approaching these lifestyle clinics and also observe any possible change in the trend.

\section{Methods}

\subsection{Study design}

The medical records of patients who had received at least one session of any form of Yoga and Naturopathy treatments at various government wings of Yoga and Naturopathy sectors in Tamil Nadu between 1 January 2015 and 31 December 2018 were retrospectively reviewed.

\subsection{Data sources}

The information was abstracted from various government Yoga \& Naturopathy centers/Lifestyle clinics in Tamilnadu, which includes the total number of outpatients, name, and frequency of diseases diagnosed and treatments offered. Naturopathy and Yoga therapies are provided to patients through various centers/Lifestyle clinics set across Tamilnadu in primary health centers under national rural health mission (NRHM), various district headquarters hospitals (DHQHpl) and Medical college hospitals (MCH), including multi-super specialty hospitals. Total of 177 Yoga and Naturopathy centers are running in the government sector. As per available disease, code patients were classified and treated accordingly.

\subsection{Study criteria}

Patients who were treated as outpatients at the Yoga and Naturopathy wings in government hospitals were included. The same patient could be duplicated because he or she could have been treated for new pains, discomforts or diagnosis. Therefore, if the same patient was treated for a different diagnosis code, we considered this case to be a new patient.

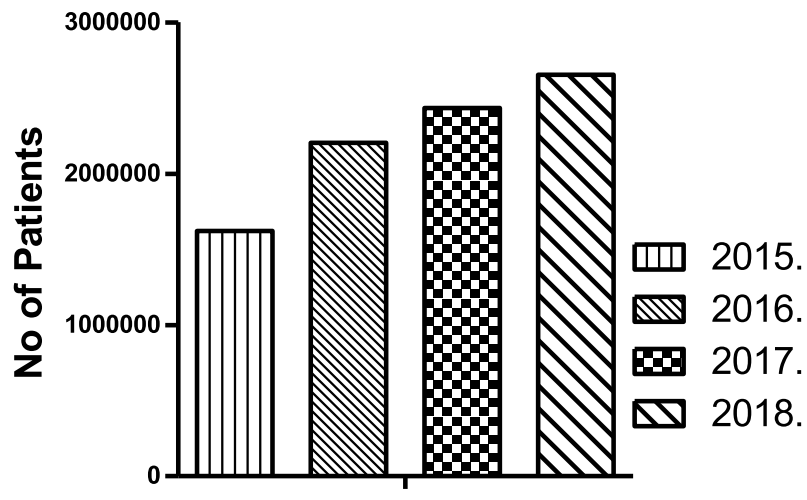

\section{Years}

Figure. 1. Number of patients visited.

\subsection{Data synthesis}

A descriptive statistical analysis was conducted and categorical data are presented as percentage and frequency.

\section{Results}

The total number of outpatients approached from the period of 2015-2018 was 8,914,820. There was a positive increase in trend which reflects that the patients visited in various Yoga and Naturopathy centers were increasing tremendously since 2015 (Fig. 1). Of the patients identified, most patients visited the NRHM as outpatients (3909549/8914820, 44\%). The patients visited in other centers like DHQHpl was 31\% (2811044/8914820) and MCH was 25\% (2194227/ 8914820) (Fig. 2). Out of these patients, most frequently (>50\%) visited patients conditions were shown in Fig. 3.

Diabetes was the most common individual health condition among the patients approached in various centers. OP visits with diabetes condition was highest in the urban centers than in the district headquarters or rural centers (84\% in $\mathrm{MCH}, 78 \%$ in $\mathrm{DHQHpl}$, and $64 \%$ in NRHM). Lumbago was the second commonest individual condition among the patients consulted in MCH (80\%). In NRHM centers, Osteoarthritis of Knee (OAK) was the most prevalent (78\%) condition than other centers (MCH-62\% and DHQHpl - 68\%). Hypertension condition was similar among the various centers of Yoga and Naturopathy (MCH-68\%, DHQHpl-62\%, and NRHM -62\%). Obesity (MCH-74\%, DHQHpl-67\%, and NRHM-60\%) and Lumbar spondylosis (MCH-72\%, DHQHpl-68\%, and NRHM-60\%) conditions also reflected a

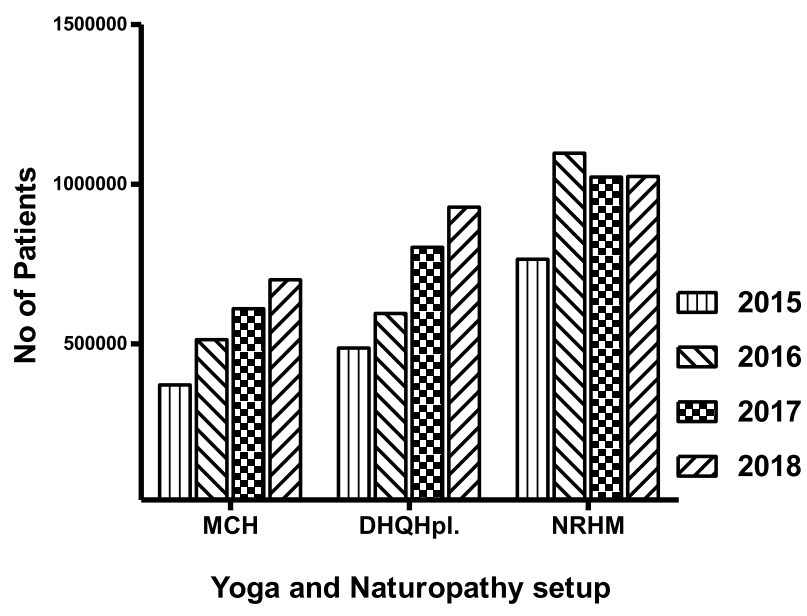

Figure. 2. Number of patients visited at various Yoga \& Naturopathy centers. 


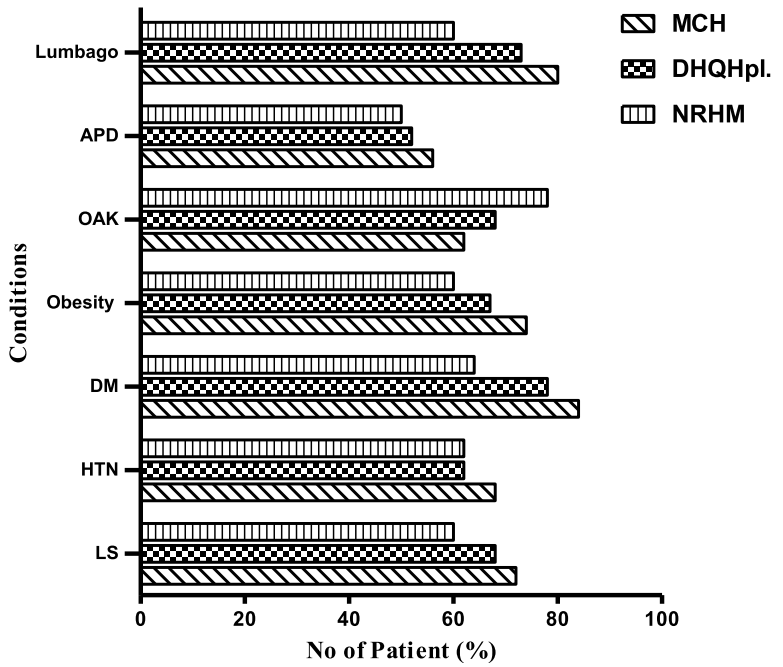

Figure. 3. Percentage of conditions with patients approached Yoga \& Naturopathy centers.

Table 1

List of treatments or therapies available in various yoga and naturopathy government settings in Tamilnadu.

\begin{tabular}{ll}
\hline S. No & List of treatments/therapies available \\
\hline 1 & Yoga therapy \\
2 & Hydrotherapy (water application in various temperature and mode which \\
& includes hip bath, spinal bath, steam bath, packs \& compress) \\
3 & Mud therapy (with mud/clay) \\
4 & Magnetotherapy \\
5 & Acupuncture/acupressure \\
6 & Diet therapy/Plant based natural supplements \\
7 & Colour therapy \\
8 & Massage (partial parts of the body based on conditions) \\
9 & Fasting therapy \\
10 & Auriculotherapy \\
11 & Reflexology \\
12 & Aromatherapy \\
13 & Lifestyle counselling
\end{tabular}

high percentage of approach among the various centers. The acid peptic disorder (APD) is the least among the most common condition with patients approached Yoga and Naturopathy centers (MCH-56\%, DHQHpl-52\%, and NRHM-50\%). The list of various Yoga and Naturopathy treatments given to the patients approached with various conditions were listed in Table-1. Facilities available at various centers are shown in Table- 2 .

\section{Discussion}

A positive trend with a year-on-year increase in the number of people turning towards the 'Lifestyle clinics' is evident through the available data. The increase in trend mirrors the increase in the prevalence of NCDs. ${ }^{28-30}$ Most patients visited the clinics with musculoskeletal disorders which is in line with previous reports on CAM therapies, ${ }^{1,31}$ followed by metabolic disorders. With an increase in the demand for CAM continues to rise worldwide, health care systems in some countries have already started to integrate CAM therapies into their conventional medical care. ${ }^{32}$ For instance, several Norwegian public and private hospitals seem to integrate the use of CAM, especially acupuncture, during delivery. ${ }^{33}$ In the state of Washington (U.S.A), $86 \%$ of hospices offer CAM to their patients. ${ }^{34}$

Reports from Australia, UK, and USA ${ }^{35-37}$ emphasize the need to improve communication between physicians and patients about their CAM usage; openness and non-judgemental communication are
Table 2

List of instruments/items available in various yoga and naturopathy government settings in Tamilnadu.

\begin{tabular}{|c|c|}
\hline S. No & List of Instruments/Items available \\
\hline 1 & Agmark Gingelly oil \\
\hline 2 & Disposable acupuncture needle ( 1 inch size) \\
\hline 3 & Disposable acupuncture needle ( $1 / 2$ inch size) \\
\hline 4 & Moxa stick \\
\hline 5 & Disposable jalaneti pot \\
\hline 6 & Disposable eye wash cup \\
\hline 7 & Epsom salt \\
\hline 8 & Plastic Enema can \\
\hline 9 & Surgical absorbable cotton $500 \mathrm{gm}$ roll with surgical spirit $-500 \mathrm{ml}$ \\
\hline 10 & Hand sanitizer \\
\hline 11 & Infraphil lamp bulb \\
\hline 12 & Sterilized mud packs \\
\hline 13 & $\begin{array}{l}\text { Packs-Chest, legs, Arm, Knee, Abdomen, GH pack, Renal, Full wet sheet } \\
\text { pack }\end{array}$ \\
\hline 14 & Facial sauna \\
\hline 15 & Acupressure \& Reflexology kit \\
\hline 16 & Aroma oil- lemon grass \\
\hline 17 & Aroma oil- pepper mint \\
\hline 18 & Aroma oil- Basil oil \\
\hline 19 & Aroma oil- Eucalyptus oil \\
\hline 20 & Aroma oil -Sandal wood oil \\
\hline 21 & Aroma oil -Camphor oil \\
\hline 22 & Aroma oil- Neem oil \\
\hline 23 & Aroma oil- Ajwain oil \\
\hline 24 & Mustard power \\
\hline 25 & Ice bag \\
\hline 26 & Hot water bag \\
\hline 27 & Thick Jamukkalam (gundu) as Yoga mat \\
\hline 28 & Wax \\
\hline 29 & Bermuda grass powder \\
\hline 30 & Curry leaves powder \\
\hline 31 & Wheatgrass powder \\
\hline 32 & Indian Gooseberry power \\
\hline 33 & Land caltrophus powder \\
\hline 34 & Holly basil powder \\
\hline 35 & Terminalia chebula powder \\
\hline 36 & Drumstick powder \\
\hline 37 & Fenugreek powder \\
\hline 38 & Solanum trilobatum powder \\
\hline 39 & Senna auriculata powder \\
\hline 40 & Phyllanthusniruri powder \\
\hline 41 & Soap oil \\
\hline 42 & Gray cloth kada \\
\hline 43 & Honey \\
\hline 44 & $\begin{array}{l}\text { Hydrotherapy equipments- Steam bath cabin, hip bath tub and spinal } \\
\text { bath tub. }\end{array}$ \\
\hline 45 & Magnet belt (Head, waist, wrist) \\
\hline
\end{tabular}

essential to determine the risks of herb-drug interactions and potential complications. ${ }^{7}$ However, Naturopathy is a more safe form of CAM therapy as no drugs or herbal 'combinations' are administered internally. This ensures that there are no risks of adverse 'herb-drug interaction' through Yoga \& Naturopathy treatments. Nevertheless, patients were requested to communicate with their physicians and keep them informed of the CAM therapies that they are undergoing at the 'Lifestyle clinics'.

A team of one qualified Yoga \& Naturopathy physician, a male therapist, a female therapist and a multipurpose worker is available at every Lifestyle clinics/centers. Evidence-based Yoga and Naturopathy therapies including mud therapy, ${ }^{38,39}$ hydrotherapy, ${ }^{40,41}$ fasting therapy, ${ }^{42,43}$ acupuncture, ${ }^{44}$ reflexology, ${ }^{45,46}$ massage, ${ }^{47,48}$ chromotherapy, ${ }^{49-51}$ magneto therapy ${ }^{52,53}$ and yoga ${ }^{13,54}$ are provided at these lifestyle clinics. Alongside these natural therapies, counselling on lifestyle modifications including diet, physical activity, sleep, and stress management are provided, which are tailor-made based on an individual's lifestyle and practical feasibility in incorporating the prescribed lifestyle modifications in their everyday life. Apart from disease management, increased number of individuals also turn to the Lifestyle 
clinics for primary and secondary prevention of diseases. This is of great importance in reducing the disease burden as well as the economic burden it lays upon on a developing country like India.

\subsection{Strengths and limitations}

Inclusion of data from both rural and urban population is one of the major strengths of the study, as the care-seeking behaviour for NCDs was found to be increased in the rural set-up in our study when compared to the urban population. Increase in trend observed in our lifestyle clinics is positive and encouraging. However, follow up data on the progress of their health conditions would have added more value and it was not possible because of the outpatient population which is one of the limitations of the study.

\subsection{Future directions}

Attitude towards CAM is becoming more positive across the world, and most health care systems and professionals worldwide wish to include CAM into hospitals and healthcare settings. ${ }^{1}$ The positive trend in the usage of CAM therapies could be seen in our 'Lifestyle clinic' model as well. There is a continuous and steady increase in the number of patients visiting Lifestyle clinics. Patient demand is the main reason why hospitals decide to provide a particular type of CAM therapy ${ }^{32}$ and with increasing demand in our 'Lifestyle clinic' model, we urge that these Lifestyle clinics should be expanded further, serving a much larger population to combat the rampant increase in lifestyle disorders worldwide. Recruitment of suitably qualified and trained healthcare professionals in these lifestyle clinics would greatly help reduce the disease burden to a larger extent, enabling to serve a larger group of people through evidence-based practice. Future studies including data on the effectiveness of the interventions provided at these lifestyle clinics on NCDs would provide us with definitive directions on future implementation of these lifestyle clinics across the globe.

\section{Declaration of competing interest}

Nil.

\section{References}

1. Jacobsen R, Fønnebø V, Foss N, Kristoffersen AE. Use of complementary and alternative medicine within Norwegian hospitals. BMC Complement Altern Med. 2015;15(1):275

2. Stange R, Amhof R, Moebus S. Complementary and alternative medicine: attitudes and patterns of use by German physicians in a national survey. J Altern Complement Med. 2008;14(10):1255-1261.

3. Ali-Shtayeh MS, Jamous RM, Jamous RM. Complementary and alternative medicine use amongst Palestinian diabetic patients. Complement Ther Clin Pract. 2012;18(1):16-21.

4. Alrowais NA, Alyousefi NA. The prevalence extent of Complementary and Alternative Medicine (CAM) use among Saudis. Saudi Pharm J. 2017;25(3):306-318

5. Falci L, Shi Z, Greenlee H. Peer Reviewed: Multiple Chronic Conditions and Use of Complementary and Alternative Medicine Among US Adults: Results from the 2012 National Health Interview Survey. Preventing chronic disease; 2016.

6. Clarke TC, Black LI, Stussman BJ, Barnes PM, Nahin RL. Trends in the use of complementary health approaches among adults: United States, 2002-2012. Natl Health Stat Rep. 2015(79):1.

7. Harris P, Cooper K, Relton C, Thomas K. Prevalence of complementary and alternative medicine (CAM) use by the general population: a systematic review and update. Int J Clin Pract. 2012;66(10):924-939.

8. Burton A, Smith M, Falkenberg T. Building WHO's global strategy for traditiona medicine. Eur J Integr Med. 2015;7(1):13-15.

9. Smith M, Burton A, Falkenberg T. World Health Organization Traditional Medicine Strategy 2014-2023. New strategy for traditional and complementary medicine includes the development and use of herbal medicinal preparations. HerbalEGram. 2014;11(5).

10. Astin JA. Why patients use alternative medicine: results of a national study. Jama. 1998;279(19):1548-1553

11. Chibwana AI, Mathanga DP, Chinkhumba J, Campbell CH. Socio-cultural predictors of health-seeking behaviour for febrile under-five children in Mwanza-Neno district, Malawi. Malar J. 2009;8(1):219.

12. Eisenberg DM, Davis RB, Ettner SL, et al. Trends in alternative medicine use in the United States, 1990-1997: results of a follow-up national survey. Jama.
1998;280(18):1569-1575

13. Venugopal V, Rathi A, Raghuram N. Effect of short-term yoga-based lifestyle intervention on plasma glucose levels in individuals with diabetes and pre-diabetes in the community. Diabetes Metab Syndrome: Clin Res Rev. 2017;11:S597-S599.

14. Thind H, Scott-Sheldon L, Lantini R, et al. The Effects of Yoga on Adults with Type II Diabetes: A Systematic Review and Meta-Analysis. 2017; 2017.

15. Cramer H, Langhorst J, Dobos G, Lauche R. Yoga for metabolic syndrome: a systematic review and meta-analysis. Eur J Prev Cardiol. 2016;23(18):1982-1993.

16. Park S-H, Han KS. Blood pressure response to meditation and yoga: a systematic review and meta-analysis. J Altern Complement Med. 2017;23(9):685-695.

17. Prankel S. Hydrotherapy in practice. Practice. 2008;30(5):272-277.

18. Roelandts R. The history of phototherapy: something new under the sun? J Am Acad Dermatol. 2002;46(6):926-930.

19. Bellometti S, Cecchettin M, Galzigna L. Mud pack therapy in osteoarthrosis: changes in serum levels of chondrocyte markers. Clin Chim Acta. 1997;268(1-2):101-106.

20. Azeemi STY, Raza M. A critical analysis of chromotherapy and its scientific evolution. Evid Based Complement Altern Med. 2005;2(4):481-488.

21. Jacobson JI. A look at the possible mechanism and potential of magneto therapy. $J$ Theor Biol. 1991;149(1):97-119.

22. Hondras MA, Linde K, Jones AP. Manual therapy for asthma. Cochrane Database Syst Rev. 2002(3),

23. Yamamoto H, Suzuki J, Yamauchi Y. Psychophysiological study on fasting therapy. Psychother Psychosom. 1979;32(1-4):229-240.

24. Franco OH, Chowdhury R, Troup J, et al. Use of plant-based therapies and menopausal symptoms: a systematic review and meta-analysis. Jama. 2016;315(23):2554-2563.

25. Yeung W-F, Chung K-F, Poon MM-K, et al. Acupressure, reflexology, and auricular acupressure for insomnia: a systematic review of randomized controlled trials. Sleep Med. 2012;13(8):971-984.

26. Jagtenberg T, Evans S, Grant A, Howden I, Lewis M, Singer J. Evidence-based medicine and naturopathy. J Altern Complement Med. 2006;12(3):323-328.

27. Pizzorno JE, Murray MT. Textbook of Natural Medicine-E-Book. Elsevier Health Sciences; 2012.

28. Collaboration NRF. Trends in adult body-mass index in 200 countries from 1975 to 2014: a pooled analysis of 1698 population-based measurement studies with $19 \cdot 2$ million participants. The Lancet. 2016;387(10026):1377-1396.

29. Ogurtsova K, da Rocha Fernandes J, Huang Y, et al. IDF Diabetes Atlas: global estimates for the prevalence of diabetes for 2015 and 2040. Diabetes Res Clin Pract. 2017; 128:40-50

30. Bennett JE, Stevens GA, Mathers CD, et al. NCD Countdown 2030: worldwide trends in non-communicable disease mortality and progress towards Sustainable Development Goal target 3.4. The Lancet. 2018;392(10152):1072-1088.

31. Bauer BA, Tilburt JC, Sood A, Li G-X, Wang S-h. Complementary and alternative medicine therapies for chronic pain. Chin J Integr Med. 2016;22(6):403-411.

32. Knutson L, Johnson PJ, Sidebottom A, Fyfe-Johnson A. Development of a hospitalbased integrative healthcare program. J Nurs Adm. 2013;43(2):101-107.

33. Salomonsen LJ, Skovgaard L, La Cour S, Nyborg L, Launsø L, Fønnebø V. Use of complementary and alternative medicine at Norwegian and Danish hospitals. BMC Complement Altern Med. 2011;11(1):4.

34. Kozak LE, Kayes L, McCarty R, et al. Use of complementary and alternative medicine (CAM) by Washington State hospices. Am J Hospice Palliat Med. 2009;25(6):463-468

35. MacLennan AH, Myers SP, Taylor AW. The continuing use of complementary and alternative medicine in South Australia: costs and beliefs in 2004. Med J Aust. 2006;184(1):27-31.

36. Barnes PM, Bloom B, Nahin RL. Complementary and Alternative Medicine Use Among Adults and Children; United States. vol. 2008. 2007; 2007.

37. Hunt KJ, Coelho HF, Wider B, et al. Complementary and alternative medicine use in England: results from a national survey. Int J Clin Pract. 2010;64(11):1496-1502.

38. Fraioli A, Mennuni G, Fontana M, et al. Efficacy of spa therapy, mud-pack therapy, balneotherapy, and mud-bath therapy in the management of knee osteoarthritis. A systematic review. BioMed Res Int. 2018;2018.

39. Fioravanti A, Bacaro G, Giannitti C, et al. One-year follow-up of mud-bath therapy in patients with bilateral knee osteoarthritis: a randomized, single-blind controlled trial. Int J Biometeorol. 2015;59(9):1333-1343.

40. Sawant RS, Shinde SB. Effect of hydrotherapy based exercises for chronic nonspecific low back pain. Indian J Physiother Occup Ther. 2019;13(1).

41. Mooventhan A, Nivethitha L. Scientific evidence-based effects of hydrotherapy on various systems of the body. N Am J Med Sci. 2014;6(5):199.

42. Templeman I, Gonzalez JT, Thompson D, Betts JA. The role of intermittent fasting and meal timing in weight management and metabolic health. Proc Nutr Soc. 2019:1-12.

43. Mattson MP, Longo VD, Harvie M. Impact of intermittent fasting on health and disease processes. Ageing Res Rev. 2017;39:46-58.

44. Cao H-J, Yu M-L, Wang L-Q, Fei Y-T, Xu H, Liu J-P. Acupuncture for primary insomnia: an updated systematic review of randomized controlled trials. J Altern Complement Med. 2019;25(5):451-474.

45. Kim J-I, Lee MS, Kang JW, Choi DY, Ernst E. Reflexology for the symptomatic treatment of breast cancer: a systematic review. Integr Cancer Ther. 2010;9(4):326-330.

46. Moghimi-Hanjani S, Mehdizadeh-Tourzani Z, Shoghi M. The effect of foot reflexology on anxiety, pain, and outcomes of the labor in primigravida women. Acta Med Iran 2015;53(8):507-511.

47. Barreto D, Batista M. Swedish massage: a systematic review of its physical and psychological benefits. Adv Mind Body Med. 2017;31(2):16-20.

48. Cheraghbeigi N, Modarresi M, Rezaei M, Khatony A. Comparing the effects of massage and aromatherapy massage with lavender oil on sleep quality of cardiac 
patients: a randomized controlled trial. Complement Ther Clin Pract. 2019;35:253-258.

49. Grote V, Kelz C, Goswami N, Stossier H, Tafeit E, Moser M. Cardio-autonomic control and wellbeing due to oscillating color light exposure. Physiol Behav. 2013;114:55-64.

50. Brainard GC, Hanifin JP, Warfield B, et al. Short-wavelength enrichment of polychromatic light enhances human melatonin suppression potency. $J$ Pineal Res. 2015;58(3):352-361.

51. Radeljak S, Žarković-Palijan T, Kovačević D, Kovač M. Chromotherapy in the regulation of neurohormonal balance in human brain-complementary application in modern psychiatric treatment. Coll Antropol. 2008;32(2):185-188.
52. Funk RH, Knels L, Augstein A, Marquetant R, Dertinger HF. Potent stimulation of blood flow in fingers of volunteers after local short-term treatment with low-frequency magnetic fields from a novel device. Evid Based Complement Altern Med. $2014 ; 2014$.

53. Gessi S, Merighi S, Bencivenni S, et al. Pulsed electromagnetic field and relief of hypoxia-induced neuronal cell death: the signaling pathway. $J$ Cell Physiol. 2019;234(9):15089-15097.

54. Kuppusamy M, Kamaldeen D, Pitani R, Amaldas J, Shanmugam P. Effects of Bhramari Pranayama on health-a systematic review. J Tradit Complementary Med. 2018;8(1):11-16. 